\title{
ANALYSIS OF LOAD SHARING CAPABILITY OF A SERIES-CONNECTED TWIN SYNCHRONOUS MOTOR DRIVE COUPLED TO A COMMON LOAD SHAFT BY GEARING
}

\author{
I. K. Onwuka ${ }^{1, *}$ and E. S. Obe ${ }^{2}$

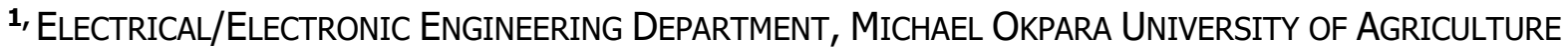 \\ UMUDIKE, ABIA STATE, NIGERIA \\ 2, EleCtrical ENGINEERING DePARTMENT, UNIVERSITY OF NigERIA NSUKKA, ENUGU STATE, NIGERIA \\ Email addresses: ${ }^{1}$ onwuka.ifeanyichukwu@mouau.edu.ng, ${ }^{2}$ simon.obe@unn.edu.ng
}

\begin{abstract}
Torque limitations on gear teeth led to the use of two motors on opposite sides of the gear to drive large grinding mills. For such systems, motor overheating and rapid gear-teeth wear have been observed, especially when using synchronous motors due to load imbalance between the two motors. This paper studied a drive system consisting of two separate three-phase synchronous motors whose phase windings are split into two sections in a manner that makes them appear as six-winding machines, and then each of the resulting six windings of one motor are connected in series with those of the other motor, with no phase transposition, such that only three terminals of each motor are available to be connected to supply. The field windings are connected in parallel to the same source. Again, the motors, running on separate shafts, are connected to a common load shaft through a speed reduction gear driven through pinions. A detailed mathematical model is developed in the q-d axis, and the system is implemented on the MATLAB/SIMULINK environment. $A$ circumferential error in the girth gear was modeled to introduce load imbalance. It is observed that despite the load imbalance, the stator currents and the load torque seen by the two motors are the same. However, a variation is observed in their rotor angles. This suggests that while the motor units inherently share the mill load equally thereby removing the possibility of motor overheating, the varying rotor angle may represent a problem for the motor shafts.
\end{abstract}

Keywords: Six-winding Machine, Synchronous Motors, Series-Connected, Common Load Shaft, Speed Reduction Gear, q-d Axis.

\section{INTRODUCTION}

Gearing limitations due to excessive torque on the gear-teeth of gears used in high power grinding mills led to the emergence of twin-motor drive systems [1, 2]. One critical issue in twin-motor drive systems is that the two motors must rotate coordinately [3]. In twin motor drive systems, the slip-ring Induction motors are often preferred to synchronous motors due to their inherent ability to minimize unbalanced loading between the two motors [4], arising due to gear run-out or gear misalignment, or manufacturing errors and tolerance in the girth gear. For the twinsynchronous motor drives, the angular position of the motor shafts are observed to vary slowly, and the same with their angular speed, culminating in variation of torque produced by the respective motors. This leads to rapid wearing of the gears - which exacerbates the problem, and to motor over heating due to the possible over-loading of one motor unit. But the higher efficiency and power factor correcting ability of synchronous motors makes them still attractive for such drive systems, especially since twinmotor drive systems are very high power systems [4]. Such systems usually find application in mineral grinding mills and cement grinding mills $[2,4]$.

* Corresponding author, tel: +234-806-016-8333 
Some efforts have been made to resolve this problem by many authors. Most of these solutions have been observed to be either expensive $[2,5]$, or involves a complex rotor circuit [6] or stator frame [2]. A number of patents have also been obtained which propose solution to the load share problem between two synchronous motors coupled to a common shaft [7 10]. In this era of high power solid state electronics, the use of converters and load sharing regulators are other possible solutions $[1,2,4]$

To the best knowledge of the authors, the system proposed in [9] has not been analytically studied, theoretically or experimentally. It is a two-motor drive system with a special stator winding arrangement, which also involves the series stator winding connections of the two motor units, and the two motor units drive a common load through pinions coupled to a speed reducing gear train.

Two-motor drives with series stator winding connection of the two motor units have been studied before [ $11-12]$. There is a sharp difference between these systems and the one in the present study. Multiphase Series-connected motors have also been studied [13 - 14], with the aim of achieving independent vector control of the motors through appropriate phase winding transposition while supplying them from the same VSI. However, there is no mechanical coupling of the two motor units, unlike the system in the present study.

\section{SYSTEM DESCRIPTION}

Figure 1 shows the mechanical coupling of the two motor units so that they contribute to the same load torque. While the motors rotate in the clockwise direction, the girth gear rotates in the anti-clockwise direction.
Figure 2 shows the stator winding connection between the two motor units in this drive arrangement. Each phase of each motor is split into two winding sections, and the winding sections are designated $s 1$ and $s 2$ windings respectively. The $s 1$ windings of the first motor are connected in series with the $s 2$ windings of the second motor, and the $s 1$ windings of the second motor are connected in series with the $s 2$ windings of the first motor. The field windings are connected in parallel. Moreover, this study assumes that the motors are electrically identical. Apparently, each motor has a six-winding stator arrangement and may be analyzed as a two three-phase stator machine. Motor units with two three-phase stator windings are the usual sixphase or quasi six-phase machines and have been studied by several authors $[15,16,18]$. However in the present study, stator winding displacement angle between the two three-phase winding sets is assumed zero to maintain a three-phase system.

From the known parameters of a three phase motor [17], the parameters of the motor units were obtained by phase belt split $[15,18]$ and presented in Table 1 . In Table 1, one of the stator winding sets was assumed as the reference winding.

\section{SYSTEM MATHEMATICAL MODEL}

From figure 2, the applied voltages are given by:

$$
V_{n}=V_{m} \cos \left(\omega_{e} t-\frac{2 \pi k}{3}\right)
$$

Where $k=0,1$, or 2 for $n=a$, $b$, or c-phase, respectively.

These voltages applied to the $s 1$ terminals supply for the phase voltages in both the $s 1$ winding of one motor and the $s 2$ winding of the other motor.

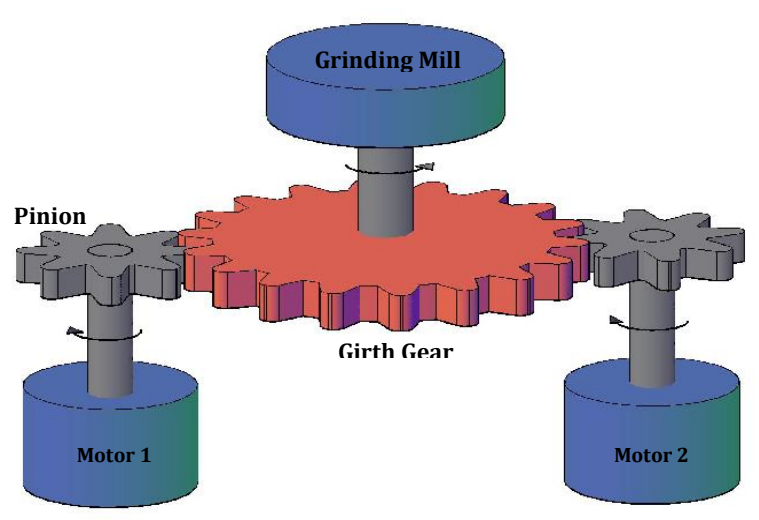

Figure 1: Two Synchronous Motor Mill drive

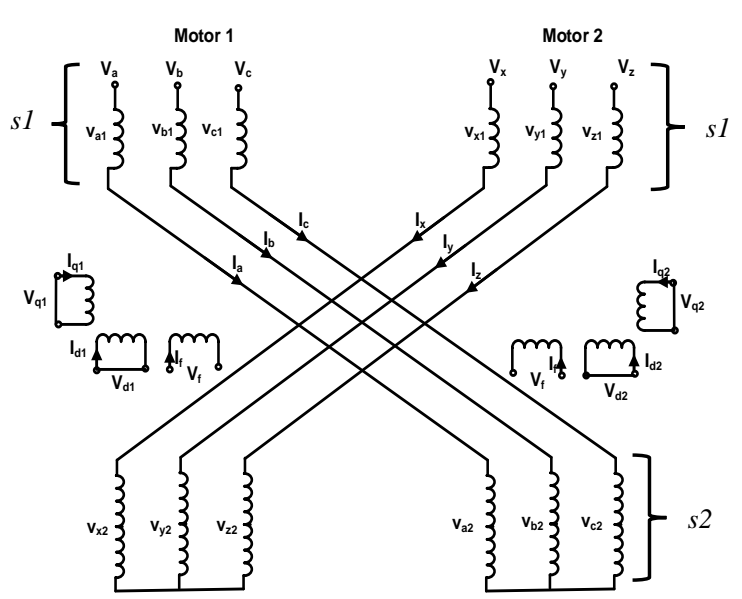

Figure 2: The Drive Motors Winding Connection 
Table 1: Parameters of the Motors Considered

\begin{tabular}{|c|c|c|}
\hline Parameter & $\begin{array}{l}\text { Conventional 3- } \phi \\
\text { Motor }\end{array}$ & $\begin{array}{l}\text { 3- } \phi \text { Six-Winding } \\
\text { Motor }\end{array}$ \\
\hline Winding Pitch factor, $\mathrm{k}_{\mathrm{p}}$ & 0.9659 & 0.9659 \\
\hline Winding Distribution factor, $\mathrm{kd}_{\mathrm{d}}$ & 0.9598 & 0.9937 \\
\hline $\mathrm{q}$-axis magnetizing reactance, $\mathrm{X}_{\mathrm{mq}}$ & $1.483 \Omega$ & $0.3974 \Omega$ \\
\hline d-axis magnetizing reactance, $X_{m d}$ & $2.42 \Omega$ & $0.6485 \Omega$ \\
\hline Rotor q-axis leakage reactance, $X_{\text {Iqr }}$ & $0.597 \Omega$ & $0.1600 \Omega$ \\
\hline Rotor $\mathrm{d}$-axis leakage reactance, $\mathrm{X}_{\mathrm{Idr}}$ & $0.574 \Omega$ & $0.1538 \Omega$ \\
\hline Field winding leakage reactance, $\mathrm{X}_{\mathrm{ffr}}$ & $0.6291 \Omega$ & $0.1686 \Omega$ \\
\hline Rotor winding resistance for q-axis, $\mathrm{r}_{\mathrm{qr}}$ & $0.0904 \Omega$ & $0.0242 \Omega$ \\
\hline Rotor winding resistance for $d$-axis, $r_{d r}$ & $0.0993 \Omega$ & $0.0266 \Omega$ \\
\hline Field winding resistance, $\mathrm{rfr}$ & $0.0662 \Omega$ & $0.0171 \Omega$ \\
\hline Stator winding resistance, $r_{\mathrm{s}}$ & $0.0667 \Omega$ & $\begin{array}{l}\mathrm{r}_{\mathrm{s} 1}=0.0333 \Omega \\
\mathrm{r}_{\mathrm{s} 2}^{\prime}=0.0333 \Omega\end{array}$ \\
\hline Stator leakage reactance, $\mathrm{X}_{\mathrm{ls}}$ & $0.1212 \Omega$ & \multirow{2}{*}{$\begin{array}{l}\mathrm{X}_{\mathrm{ls} 1}=0.0358 \Omega \\
\mathrm{X}_{\mathrm{ls} 2}^{\prime}=0.0358 \Omega \\
0.0088\end{array}$} \\
\hline Leakage reactance mutual to the two winding sets, $X_{I m}$ & 0 & \\
\hline $\begin{array}{l}\text { Leakage reactance between the } \mathrm{q} \text { - and } \mathrm{d} \text {-axes of the two } \\
\text { winding sets, } \mathrm{X}_{\mathrm{Idq}}\end{array}$ & 0 & 0 \\
\hline Number of Poles, $\mathrm{P}$ & 6 & 6 \\
\hline Rated voltage, $V_{\text {Line-to-Line }}$ & $208 \mathrm{~V}$ & $208 \mathrm{~V}$ \\
\hline Rated current, Irated & $57.8 \mathrm{~A}$ & $57.8 \mathrm{~A}$ \\
\hline Inertia of unloaded motor, J & $0.08 \mathrm{~kg}-\mathrm{m}^{2}$ & $0.08 \mathrm{~kg}-\mathrm{m}^{2}$ \\
\hline
\end{tabular}

The assumption of electrical identity of the motors suggests that the applied voltage will divide between the $s 1$ and $s 2$ windings according to their turn ratio. As such, it will be observed from Figure 2 that:

$$
V_{n}=v_{n 1}+v_{n 2}=\left(r_{s 1}+r_{s 2}\right) i_{n}+p\left(\lambda_{n 1}+\lambda_{n 2}\right)
$$

Usually, the windings of one set of three-phase winding, say $s 2$, is referred to the windings of the other set of three-phase winding, say $S_{1}$. Equation (2) will be modified as follows:

$$
V_{n}^{\prime}=r_{s} i_{n}+p \lambda_{n}^{\prime}
$$

where $V_{n}^{\prime}=v_{n 1}+v_{n 2}^{\prime} ; \quad r_{s}=r_{s 1}+\frac{N_{s 2}}{N_{s 1}} r_{s 2}^{\prime}$ and $\lambda_{n}^{\prime}=$ $\lambda_{n 1}+\lambda_{n 2}^{\prime}$
The difficulty of manipulating the time varying inductance terms in the non-linear equations (2) as modified in (3) may be handled easily using the wellknown q-d axis equations in the rotor reference frame to simplify the solution which yields constant inductance terms. The following 12 voltage equations, represented in compact matrix form, describes the system:

$$
\begin{aligned}
& V_{q d o 1,2}^{\prime}=r_{s}^{\prime} i_{q d o 1,2}+\omega_{r} \lambda_{d q o 1,2}^{\prime}+p \lambda_{q d o 1,2}^{\prime} \\
& V_{q d r 1,2}^{\prime}=r_{q d r}^{\prime} i_{q d r 1,2}^{\prime}+p \lambda_{q d r 1,2}^{\prime}
\end{aligned}
$$

The flux linkages are expressed as shown in equation (6)

Where

$$
\lambda_{q d o 1,2, r}^{\prime}=\left[\begin{array}{c}
\lambda_{q d o 1}^{\prime} \\
\lambda_{q d o 2}^{\prime} \\
\lambda_{q d r 1}^{\prime} \\
\lambda_{q d r 2}^{\prime}
\end{array}\right]=\left[\begin{array}{cccc}
L_{s 1}+\frac{N_{s 2}}{N_{s 1}} L_{s 2} & \frac{N_{s 2}}{N_{s 1}} L_{s 1 s 2}+L_{s 1 s 2} & L_{s 1 r} & L_{s 2 r} \\
L_{s 1 s 2}{ }^{T}+\frac{N_{s 2}}{N_{s 1}} L_{s 1 s 2}{ }^{T} & \frac{N_{s 2}}{N_{s 1}} L_{s 2}+L_{s 1} & L_{s 2 r} & L_{s 1 r} \\
L_{s 1 r}{ }^{T} & \frac{N_{s 2}}{N_{s 1}} L_{s 2 r}{ }^{T} & L_{r} & 0 \\
\frac{N_{s 2}}{N_{s 1}} L_{s 2 r}{ }^{T} & L_{s 1 r}{ }^{T} & 0 & L_{r}
\end{array}\right]\left[\begin{array}{l}
i_{q d o 1} \\
i_{q d o 2} \\
i_{q d r 1}^{\prime} \\
i_{q d r 2}^{\prime}
\end{array}\right]
$$




$$
\begin{aligned}
& L_{s 1}=\left[\begin{array}{ccc}
L_{l s 1}+L_{m q} & 0 & 0 \\
0 & L_{l s 1}+L_{m d} & 0 \\
0 & 0 & L_{l s 1}
\end{array}\right] \\
& L_{s 2}=\left[\begin{array}{ccc}
L_{l s 2}+L_{m q} & 0 & 0 \\
0 & L_{l s 2}+L_{m d} & 0 \\
0 & 0 & L_{l s 2}
\end{array}\right] \\
& L_{s 1 s 2}=\left[\begin{array}{ccc}
L_{l m} & -L_{l d q} & 0 \\
L_{l d q} & L_{l m} & 0 \\
0 & 0 & L_{l a X}+L_{l a Y}
\end{array}\right] \\
& +\left[\begin{array}{ccc}
L_{m q} & 0 & 0 \\
0 & L_{m d} & 0 \\
0 & 0 & 0
\end{array}\right] \\
& L_{s 1 r}=L_{s 2 r}=\left[\begin{array}{ccc}
L_{m q} & 0 & 0 \\
0 & L_{m d} & L_{m d} \\
0 & 0 & 0
\end{array}\right] \\
& L_{r}=\left[\begin{array}{ccc}
L_{l q r}^{\prime}+L_{m q} & 0 & 0 \\
0 & L_{l d r}^{\prime}+L_{m d} & L_{m d} \\
0 & L_{m d} & L_{l f r}^{\prime}+L_{m d}
\end{array}\right]
\end{aligned}
$$

Since the two motors are not on the same shaft, the mechanical equations of the two motors are obtained separately. As such, the respective torque equation of the two motors will be:

$T_{e m 1}=\frac{3}{2} \frac{P}{2}\left[\left(i_{q 1}+\frac{N_{s 2}}{N_{s 1}} i_{q 2}\right) L_{m d}\left(i_{d 1}+\frac{N_{s 2}}{N_{s 1}} i_{d 2}+i_{d r 1}^{\prime}+\right.\right.$ $\left.i_{f r 1}^{\prime}\right)-\left(i_{d 1}+\frac{N_{s 2}}{N_{s 1}} i_{d 2}\right) L_{m q}\left(i_{q 1}+\frac{N_{s 2}}{N_{s 1}} i_{q 2}+\right.$ $\left.\left.i_{q r 1}^{\prime}\right)\right]$

$T_{e m 2}=\frac{3}{2} \frac{P}{2}\left[\left(\frac{N_{S 2}}{N_{S 1}} i_{q 1}+i_{q 2}\right) L_{m d}\left(\frac{N_{S 2}}{N_{s 1}} i_{d 1}+i_{d 2}+i_{d r 2}^{\prime}+\right.\right.$ $\left.i_{f r 2}^{\prime}\right)-\left(\frac{N_{s 2}}{N_{s 1}} i_{d 1}+i_{d 2}\right) L_{m q}\left(\frac{N_{s 2}}{N_{s 1}} i_{q 1}+i_{q 2}+\right.$ $\left.\left.i_{q r 2}^{\prime}\right)\right]$

The derivative of the motors angular speed will be given by:

$$
\begin{aligned}
& p \omega_{r 1}=\frac{P}{2 J}\left(T_{e m 1}-T_{L 1}\right) \\
& p \omega_{r 2}=\frac{P}{2 J}\left(T_{e m 2}-T_{L 2}\right)
\end{aligned}
$$

The angular position of the rotors on their respective shafts will be:

$$
\begin{aligned}
& \delta_{1}=\int\left(\omega_{r 1}-\omega_{e}\right) \\
& \delta_{2}=\int\left(\omega_{r 2}-\omega_{e}\right)
\end{aligned}
$$

To recover the currents in phase variables,

$$
i_{a b c x y z}=\left[\begin{array}{cc}
T\left(\theta_{r}\right)^{-1} & 0 \\
0 & T\left(\theta_{r}\right)^{-1}
\end{array}\right]\left[\begin{array}{l}
i_{q d 01} \\
i_{q d 02}
\end{array}\right]
$$

Where:

$$
T\left(\theta_{r}\right)=\frac{2}{3}\left[\begin{array}{ccc}
\cos \left(\theta_{r}\right) & \cos \left(\theta_{r}-\frac{2 \pi}{3}\right) & \cos \left(\theta_{r}+\frac{2 \pi}{3}\right) \\
\sin \left(\theta_{r}\right) & \sin \left(\theta_{r}-\frac{2 \pi}{3}\right) & \sin \left(\theta_{r}+\frac{2 \pi}{3}\right) \\
\frac{1}{2} & \frac{1}{2} & \frac{1}{2}
\end{array}\right]
$$

and $\theta_{r}=\frac{\left(\theta_{r 1}+\theta_{r 2}\right)}{2}$

\section{LOAD MODEL}

In modeling the mill load, the major consideration will be how to factor in the imperfect gear. If it is assumed that the imperfection of the gear is due to circumferential error in manufacturing, then figure 3 will be an exaggerated schematic for the system.

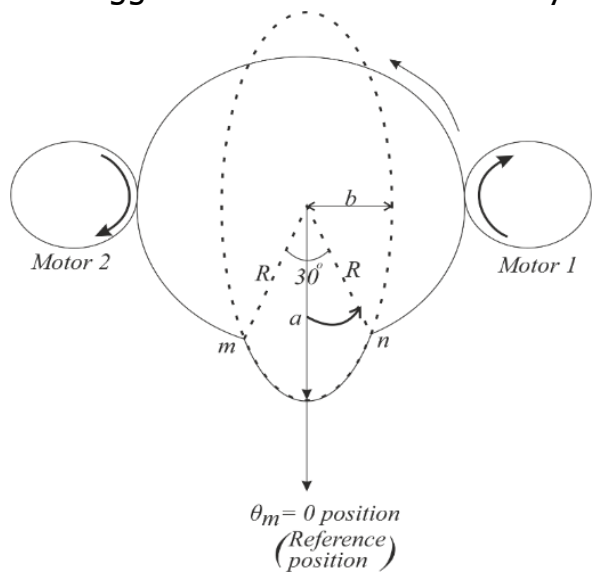

Figure 3: An Exaggerated Schematic of the imperfect gear

Table 2: Variation of the Load Torque $T_{L}$ of the Motors as the Girth Gear rotates

\begin{tabular}{lcc}
\hline Position & TL1 $_{\mathbf{L}}$ & $\mathbf{T}_{\mathbf{L} 2}$ \\
\hline $0 \frac{5}{12} \pi$ & $\frac{T_{L M}}{2}$ & $\frac{T_{L M}}{2}$ \\
$\frac{5}{12} \pi \leq \theta_{m}$ & $\frac{T_{L M} \times R}{R+\sqrt{x^{2}+y^{2}}}$ & $\frac{T_{L M} \sqrt{x^{2}+y^{2}}}{R+\sqrt{x^{2}+y^{2}}}$ \\
$\leq \frac{7}{12} \pi$ & & $\frac{T_{L M}}{2}$ \\
$0 \leq \theta_{m}$ & $\frac{T_{L M}}{2}$ & $\frac{T_{L M} \times R}{R+\sqrt{x^{2}+y^{2}}}$ \\
$\leq \frac{17}{12} \pi$ & $\frac{T_{L M} \sqrt{x^{2}+y^{2}}}{R+\sqrt{x^{2}+y^{2}}}$ & $R$ \\
$\frac{17}{12} \pi \leq \theta_{m}$ & & $\frac{T_{L M}}{2}$ \\
$\frac{19}{12} \pi$ & $\frac{T_{L M}}{2}$ & \\
$\frac{19}{12} \pi \leq \theta_{m}$ & & \\
\hline
\end{tabular}

Where $\theta_{m}$ refers to the angular position of the gear as it moves on its axis. See equation (20), $T_{L M}=$ Mill Load Torque; 
radius of the symmetric part of the gear; $x=$ $a \cos \theta_{m}$ and $y=b \sin \theta_{m}$

To obtain this load model, the following assumptions was made in modeling the load (Grinding Mill) and the gear train.

i. There is an error due to manufacturing tolerance in the girth gear.

ii. The pinions are exactly $\pi$ radians apart.

iii. The motors are rotating in the clockwise direction while the girth gear is rotating in the anticlockwise direction.

iv. The grinding mill speed is selected to be 20rpm, while the motors are 1000rpm, resulting to a gear ratio of $k=50$.

The grinding mill speed in rad/sec will be:

$$
\omega_{m}=\left(\frac{\omega_{1}+\omega_{2}}{2}\right) \times \frac{2}{P} \times \frac{1}{k}
$$

Where $\omega_{1}$ and $\omega_{2}$ are the respective speed of the first and second synchronous motors, $P$ is the number of poles of the motors and $k$ is the gear ratio.

When $\omega_{\mathrm{m}}$ is multiplied by time, $t$, a displacement angle, $\theta_{m}$ will result, in radian units.

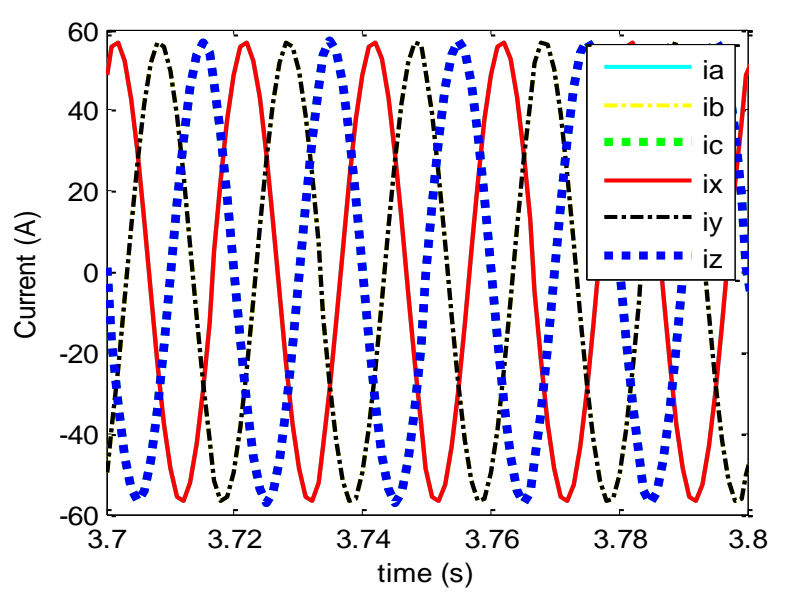

Figure 4: Stator Currents

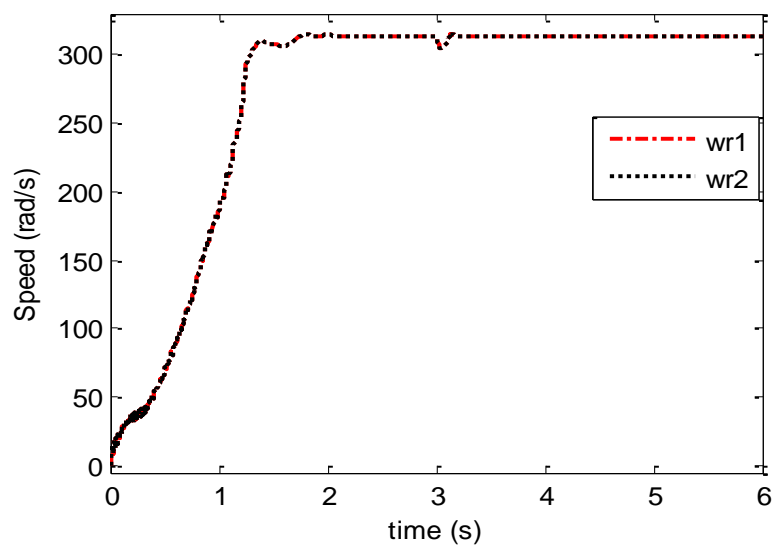

Figure 6: Angular Speed of Motors 1 and 2

$$
\theta_{m}=\omega_{m} t
$$

\section{SIMULATION RESULTS}

The simulation tool is the MATLAB/SIMULINK commercial software. The model equations from (3) to (20) was implemented using the Embedded MATLAB function. Consideration was made for two cases:

(i) Case 1: When the two motors experience the same load on their pinions, suggesting a perfect gear train.

(ii) Case 2: When the two motors experience a slight variation of load on their pinions per revolution of the mill, $180^{\circ}$ out of phase from each other.

In each case, the motors are started at the same time on no-load, and after steady state, they are loaded by a system described by the model equations earlier determined. The rated current of the three-phase motor is $57.7 \mathrm{~A}$, and this informed the rated load of the constituent motors in the SCTSMD. In each case, the load is applied after 3 seconds. The important traits observed are as follows.

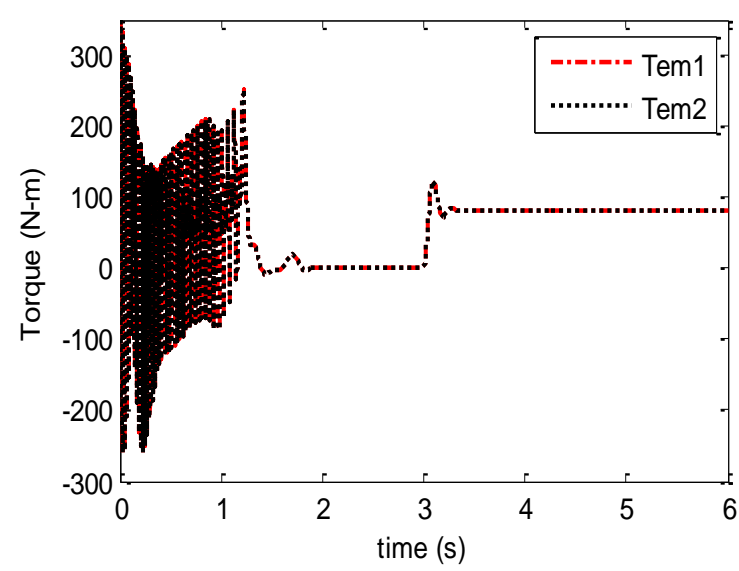

Figure 5: Torque Developed by the Motors

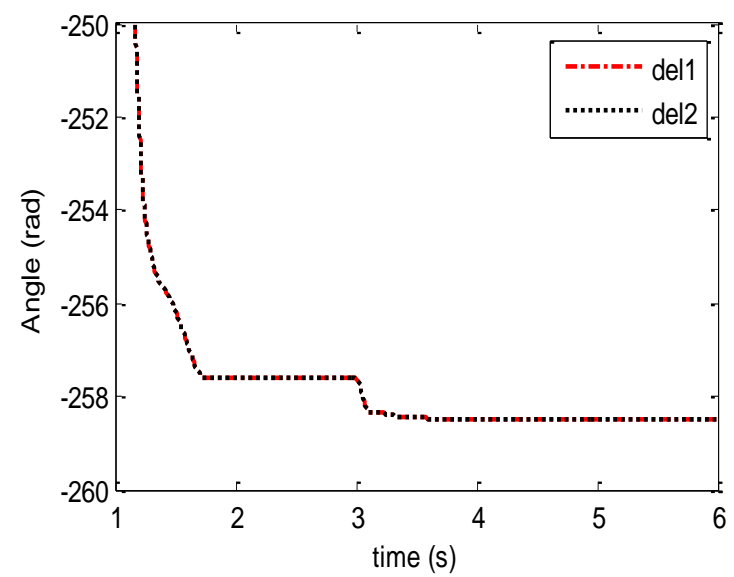

Figure 7: Load angle of Motors 1 and 2 


\subsection{Case 1: SCTSMD with balanced load on the motors}

A quick observation from figure 4 shows that the $a-$ and $x$-phases coincides, as well as the $b$ - and $y$-phases and the $c-$ and z-phases, suggesting a three-phase system with six stator windings. The same torque was developed by the two motors expectedly, as shown in figure 5. It is further observed in figure 6 that the motors rotate coordinately, and consequently, the load angles are also coordinated, as observed in figure 7 . The traits of figures 4- 7 suggests an equal sharing or distribution of the mill load on the two motors. This is desirable and represents the ideal case.

\subsection{Case 2: SCTSMD with periodically varying loads due to imperfect Gear circumference}

To observe the currents closely, the envelope of only the ' $a$ ' and ' $x$ ' windings current waveforms were plotted on the same axis in Figure 8. It was observed that the currents were equal, having determined earlier that they are in phase. This suggests that the problem of motor overheating due to load imbalance would be resolved by this drive arrangement. Developed torque was also observed equal from figure

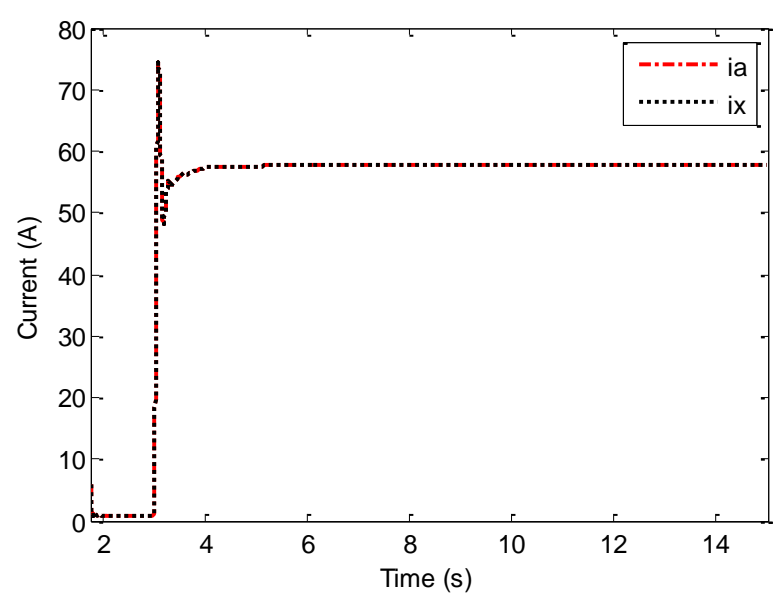

Figure 8: Phase Currents for winding ' $a$ ' and ' $x$ '

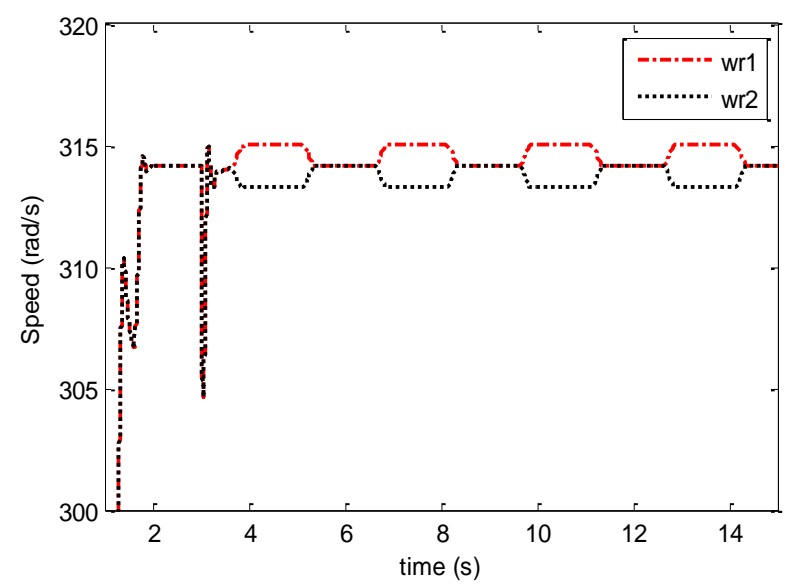

Figure 10: Angular Speed of Motors 1 and 2
9, suggesting that no gear teeth will be exposed to peak loading, thereby dealing with the problem of gear wear due to load imbalance. In Figure 10, it was observed that the motors experienced periodical angular speed difference, leading to varying load angles by the two motors as seen in Figure 11. This raises a concern to the safety of the motor shafts. The load transmitted to the motors through their pinions is shown in Figure 12 while Figure 13 captures the grinding mill angular speed.

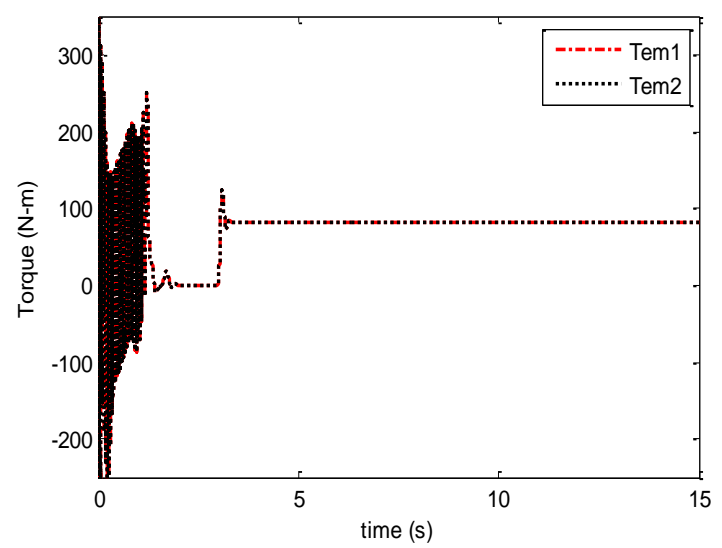

Figure 9: Torque Developed by Motors 1 and 2

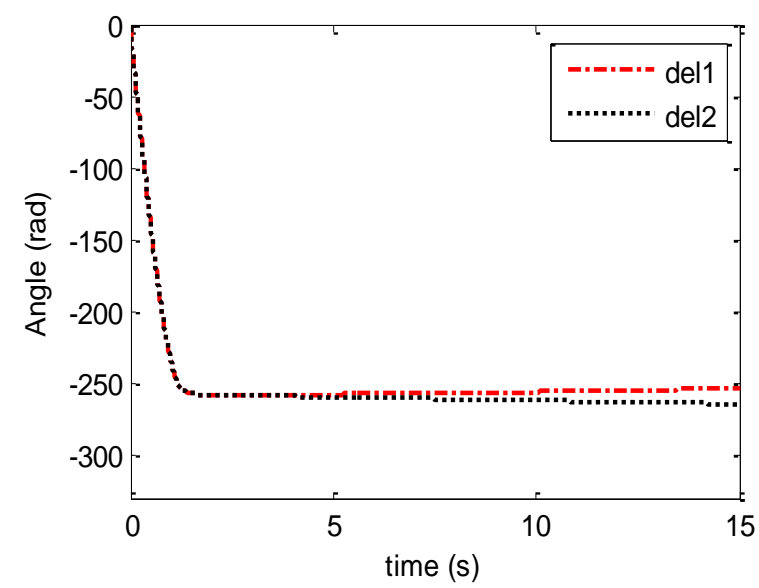

Figure 11: Load angle of Motors 1 and 2 


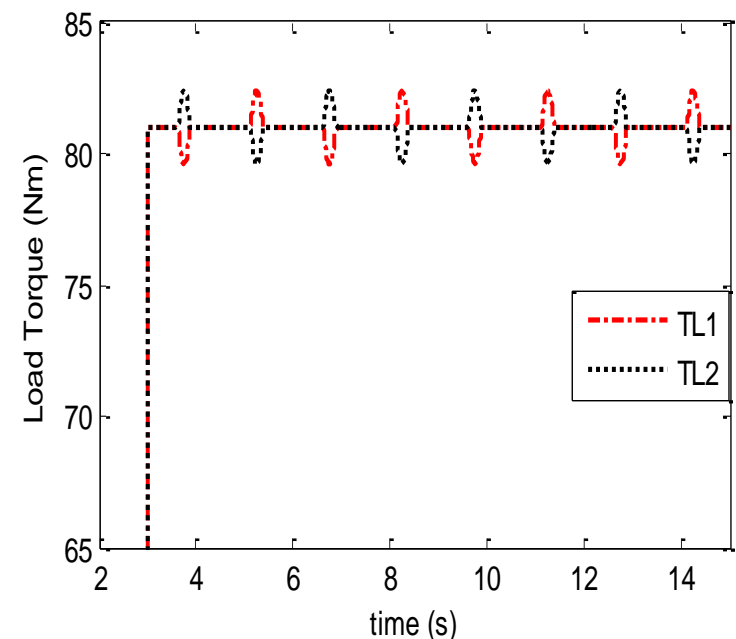

Figure 12: Load Torque transmitted to the Motor Shafts

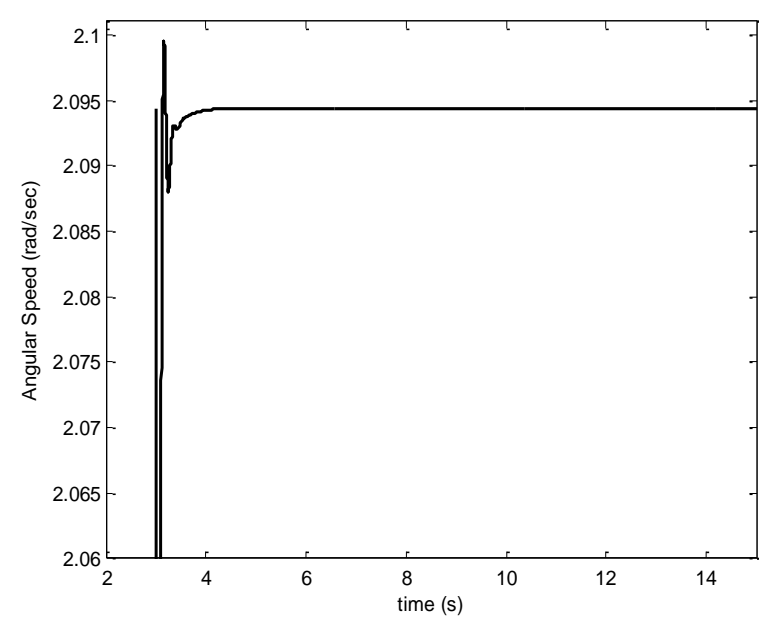

Figure 13: Grinding Mill Speed

\section{CONCLUSION}

This study covers the model development and simulation of the system of series connected twin synchronous motor drive which are connected to a common shaft and run direct on line. An investigation made to ascertain the inherent ability of the motor units in this arrangement to share the mill load equally reveals that while the mill load is shared equally by the two motors, thereby overcoming the problem of overheating by one of the two motors, the slowly varying rotor position between the two motors persists with a possibility of motor shaft breakage.

\section{REFERENCES}

[1] Arthur H. Hoffmann, John G. Trasky, "Evaluation of Large Grinding Mill Drives for the Cement Industry", IEEE Transactions on Industry Applications, Vol. IA-8, No.1, Jan/Feb 1972.

[2] R. D. Valentine, John G. Trasky, Donald R. Rippin, "Load Sharing of Dual Motor Grinding Mill Drives", IEEE Transactions on Industry Applications, Vol. IA, No.2, March/April 1977.

[3] Jose R. Rodriguez et al, "Technical Evaluation and Practical Experience of High Power Grinding Mill Drives in Mining Applications", IEEE Transactions on Industry Applications, Vol. 14, No. 3, May/June 2005.

[4] George Seggewiss et al, "Evaluation of Synchronous Motors on Grinding Mills", Cement Industry Technical Conference (CIC), 2014 IEEEIAS/PCA.

[5] Arden L. Scott, Raymond D. Valentine, "Large Grinding Mill Drives Update", IEEE Transactions on
Industry Applications, Vol. IA-18, No.6, Nov/Dec 1982.

[6] Andrew L. Mular, Dong N. Hube, Dereck John Barratt, "Mineral Processing Plant Design, Practice and Control Proceedings", pp 1983-2010, SME 2002.

[7] J. E. Nelson, "Control of Synchronous Motors on a Common Drive", United States Patent Office, 3,369,636, Patented February 20, 1968.

[8] L. A. Kilgore, Bernard S. Strait Jr., Eugene C. Whitney, "Twin Motor Drive System", United States Patent 3,735,217, Patented May 22, 1973.

[9] William L. Ringland, "Plural Eletric Motor Driving a Common Load and Having Interconnections for Power Control", United States Patent 4,208,620, Patented June 17, 1980.

[10] Kunitoshi Kato, "Apparatus for Operating Plural Poly Phase AC Motors having a Common Load", United States Patent, 4,525,656, Patented June 25, 1985.

[11] Linus U, Anih and Emeka S. Obe, "Performance analysis of a composite dual-winding reluctance machine", Energy Conversion and Management, 50(2009) $3056-3062$.

[12] Linus U. Anih, Emeka S. Obe, and Sylvester E. Abonyi, "Modelling and Performance of a Hybrid Synchronous Reluctance Machine with Adjustable $\mathrm{X}_{\mathrm{d}} / \mathrm{X}_{\mathrm{q}}$ Ratio", IET Electric Power Applications, Volume 9, Issue 2, February 2015, p. $171-182$

[13] Martin Jones, Slobodan N. Vukosavic, Emil Levi, and Atif Iqbal, "A Six-Phase Series-Connected Two-Motor Drive with Decoupled Dynamic Control", IEEE Transactions on Industry Applications Vol. 41, No. 4, July/August 2005. 
[14] Emil Levi, Martin Jones, Slobodan N. Vukosavic, Atif Iqbal, and Hamid A. Toliyat, "Modeling, Control, and Experimental Investigation of a FivePhase Series-Connected Two-Motor Drive with Single Inverter Supply", IEEE Transactions on Industrial Electronics, Vol. Vol 54, Issue 3, 2007.

[15] G. K. Singh and Derminder Singh, "Experimental Study on Six-Phase Synchronous Alternator for Stand-Alone Renewable Energy Generation", IACSIT International Journal of Engineering and Technology, Vol 4, No. 4, pp 344-347, August 2012.

[16] Pablo Castro Palavicino, M. Anibal Valenzuela, "Modeling and Evaluation of Cycloconverter-Fed
Two-Stator-Winding SAG Mill Drive - Part I: Modeling Options", IEEE Transactions on Industry Applications, Vol. 51, NO. 3, May/June 2015.

[17] J. O. Ojo, V. Ostovic, T. A Lipo, and J. C. White, "Measurement and Computation of Starting Torque Pulsations of Salient Pole Synchronous Motors", IEEE Transactions on Energy Conversion, Vol. 5, No. 1, March 1990.

[18] Schiferl Rich, "Detailed Analysis of a Six-Phase Synchronous Machine with $A C$ and DC Stator Connections", PhD Thesis submitted to the School of Electrical Engineering Purdue University, West Lafayette, Indiana, June 1982. 